\title{
Delivery of Confidential Care to Adolescent Males
}

\author{
Susan E. Rubin, MD, MPH, M. Diane McKee, MS, MD, Giselle Campos, BA, \\ and Lucia F. O'Sullivan, PbD
}

Purpose: Primary care providers' (PCPs') provision of time alone with an adolescent without the parents present (henceforth referred to as "confidential care") has a significant impact on adolescents' disclosure of risk behavior. To inform the development of interventions to improve PCPs' delivery of confidential care, we obtained the perspectives of adolescent males and their mothers about the health care concerns of adolescent males and the provision of confidential care.

Methods: This focus-group study ( 5 groups: 2 with adolescent males and 2 with mothers) used standard qualitative methods for analysis. We recruited mother/son dyads who had been seen at urban primary care practices.

Results: Adolescents' health concerns focused on pregnancy and sexually transmitted infections; mothers took a broader view. Many adolescents felt that PCPs often delivered safe sex counseling in a superficial, impersonal manner that did not add much value to what they already knew, and that their PCP's principal role was limited to performing sexually transmitted infection testing. Though adolescents cited a number of advantages of confidential care and disclosure, they expressed some general mistrust in PCPs and concerns about limits of confidentiality. Rapport and relationship building with their PCP are key elements to adolescents' comfort and increased disclosure. Overall, mothers viewed confidential care positively, especially in the context of continuity of care, but many felt excluded.

Conclusions: To increase adolescents' perception of the relevance of primary care and to foster disclosure during health encounters, our participants described the critical nature of a strong doctorpatient relationship and positive physician demeanor and personalized messages, especially in the context of a continuity relationship. Regular, routine inclusion of confidential care time starting early in adolescence, as well as discussion of the purpose and limitations of confidentiality with parents and adolescents, could lead to greater parental comfort with confidential care and increased disclosure by the adolescent. (J Am Board Fam Med 2010;23:728-735.)

Keywords: Confidentiality, Adolescents, Focus Groups, Primary Care

Most causes of adolescent morbidity and mortality are preventable and attributed to risk-taking behavior such as substance use, violence, and unprotected sexual activity. ${ }^{1,2}$ For example, adolescents and young adults aged 15 to 24 have high rates of sexually transmitted infections (STIs); they acquire nearly half of all incident STIs al-

This article was externally peer reviewed.

Submitted 23 March 2010; revised 9 June 2010; accepted 14 June 2010.

From the Department of Family and Social Medicine, Montefiore Medical Center/Albert Einstein College of Medicine, Bronx, NY (SER, MDM, GC); and the Department of Psychology, University of New Brunswick, Fredericton, New Brunswick, Canada (LFO).

Funding: This research was funded by grant no. 1R21HD054326-01A2 (MDM, principal investigator) through the Eunice Kennedy Shriver National Institute of Child Health and Human Development. Dr. Rubin's salary was supported by a fellowship grant from the New York State Empire Clinical Research Investigator Program. though they represent only $25 \%$ of the sexually active population. ${ }^{3}$ The primary care provider's (PCP's) provision of time alone with the adolescent without a parent or guardian present (hereafter referred to as "confidential care") has a significant impact on the likelihood that an adolescent will disclose risky behavior. ${ }^{4-6}$ Because concerns about privacy are paramount among minors, ${ }^{7}$ confidential care is essential for eliciting

Conflict of interest: none declared.

Corresponding author: Susan E. Rubin, MD, MPH, Department of Family and Social Medicine, Albert Einstein College of Medicine, 1300 Morris Park Avenue, Mazer 410, Bronx, NY 10461 (E-mail: surubin@montefiore.org).

See Related Commentary on Page 702. 
a sexual history and thus the provision of appropriate reproductive health care. ${ }^{8}$

Because PCPs can play an important role in addressing risk behaviors, professional organizations recommend annual preventive visits for adolescents, counseling and/or screening, ${ }^{2,9,10}$ as well as confidential care services and testing for STIs. ${ }^{9,11-13}$ However, male adolescents, especially older adolescents, infrequently access preventative health services, ${ }^{14}$ including reproductive health services, ${ }^{15,16}$ and many adolescents are not offered STI testing and counseling during routine health care encounters. ${ }^{17,18}$

With the goal of developing interventions to improve delivery by PCPs of confidential care for urban adolescents, we conducted focus groups with adolescent male users of primary care and their mothers. We sought to obtain their perspectives on (1) adolescent males' perceived health care concerns and needs with a focus on sexual and reproductive health, (2) the role of physicians in meeting those needs, and (3) their experiences around obtaining confidential sexual and reproductive health care with the adolescent's PCP. The results of a focus group study that examined this question for teenage girls and their mothers was published in 2006. ${ }^{19}$ To our knowledge, no one has explored this issue with adolescent males and their mothers.

\section{Methods}

The Institutional Review Board at the Albert Einstein College of Medicine, Bronx, NY, approved this study.

\section{Recruitment}

We identified potential mother-son dyads using Montefiore Medical Center's (Bronx, NY) clinical information system. We identified all boys aged 16 to 19 years who were seen either at a family medicine (4 sites) or pediatric (2 sites) clinic during the previous 6 months. All the sites are affiliated with an academic medical center and are located in the Bronx, NY. The mother received a recruitment letter signed by the adolescent's PCP, and an optout card to return to if they desired no further contact from project staff. The letter invited the recipients to voluntarily participate in a focus group research study with the goal of "[learning] more about how mothers and sons talk about the special health care needs of young men, and how families can work with doctors to improve the care given to teenage boys."

If the opt-out card was not returned, we attempted phone contact with the mother to assess eligibility and interest. A mother was eligible if she had been the primary female caretaker of a male aged 16 to 19 years old for at least the past 5 years. She had to be fluent in either English or Spanish. If the mother provided consent, we then invited her son to participate in a separate focus group. We attempted contact with potential participants until the focus groups were filled. Because of financial constraints, we could conduct a total of 5 groups. Because we anticipated that a proportion of the mothers would be primarily Spanish speakers, but that all the sons would be able to converse in English, we chose to conduct one group for mothers in Spanish and 2 in English; both adolescent groups were conducted in English. Our goal was to recruit 10 to 12 participants for each group to ensure 6 to 8 participants per group, a number considered to be optimal. ${ }^{20}$ Each individual participant received a $\$ 50$ stipend.

We chose to include older adolescents because they were more likely to have experience with confidential care $^{21}$ and would therefore provide a richer perspective on our topic. We included only female adult caretakers because mothers are more likely then fathers to accompany children to their medical appointments.

\section{Data Collection}

The adolescent groups were held after the mothers' groups to provide more assurance of confidentiality to the adolescents. ${ }^{19} \mathrm{We}$ collected written informed consent before conducting the focus groups and asked for anonymous background demographic data from all participants.

Graduate-level, experienced, gender-matched facilitators conducted the focus groups. One of the authors (MDM) oriented both facilitators to this project. A native Spanish speaker conducted the mothers' Spanish-speaking group. A gender-matched observer took notes in each group, and both the facilitator and observer submitted written notes to the research team after each group. The group sessions were audiotaped and later transcribed verbatim.

\section{Focus Group Guide}

We developed our focus group guide based on a review of the research literature and in consultation 
Figure 1. Recruitment of mothers.

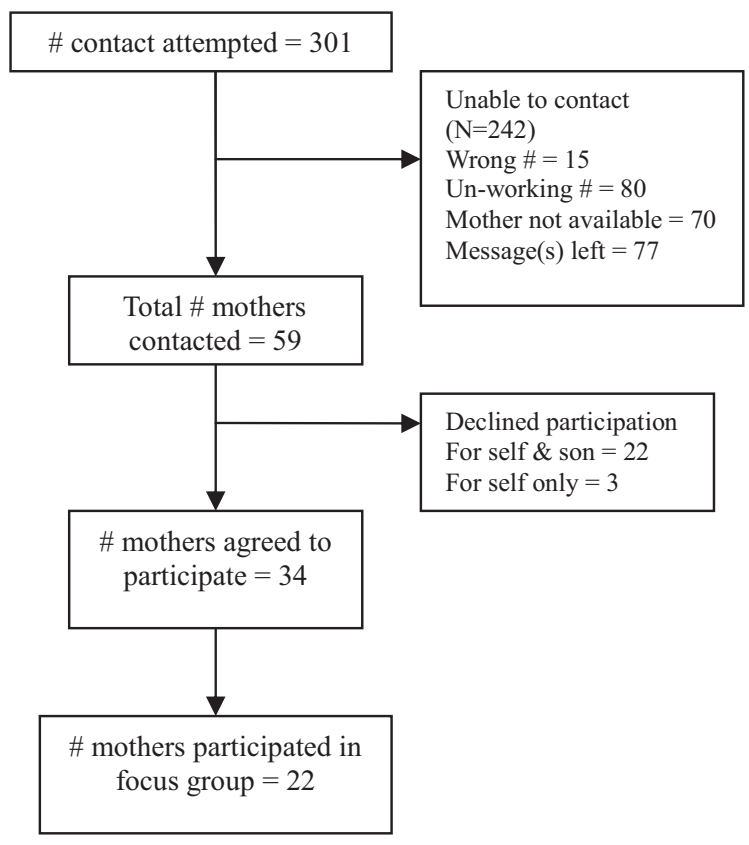

with adolescent reproductive health experts. Using a funneling technique ${ }^{20}$ with our questions, we started with broad questions (What are the main concerns that you or other teenaged males have about your health?) and then moved on to more focused questions (Thinking about your son being alone with the doctor, what are the disadvantages/ advantages or negative/positive outcomes, if any, that you think come about if a doctor talks privately with your son?).

The sons' guide queried the following general areas: adolescent males' main health concerns; the best individual(s) to give advice on these issues; communication with their mother or other adult family members about sexual health; sexual and reproductive health conversations and experiences with their physician; experience with confidential care; and clinic systems issues.

The mothers' guide was somewhat similar; it asked about their perception of the major health concerns for adolescent boys today; the best person to give advice on these issues; and familial communication about sexual and reproductive health. Mothers were also asked their opinions regarding physicians' role in caring for adolescent males; their experiences with and feelings about confidential care; and how physicians could best collaborate with mothers to meet adolescent males' health care needs.
All questions were open-ended and had a number of scripted follow-up probes. The guide was modified in an iterative fashion during subsequent focus groups to ensure complete coverage of the topics. ${ }^{22}$

\section{Research Team Members and Data Analysis}

The research team members included 2 family physicians (SER, MDM), a research coordinator (GC), and a social psychologist (LFO). All team members had experience with conducting qualitative health studies in urban settings. Two investigators (MDM, LFO) had conducted similar focus-group research with adolescent girls and their mothers. ${ }^{19}$ Two investigators (SER, MDM) provided care in family medicine clinics from which we recruited, but we did not recruit their patients.

Using the approach outlined by Crabtree and Miller, ${ }^{20}$ the researchers independently read each focus group transcript. Each team member independently identified themes; the team then reviewed each transcript excerpt by excerpt to modify and refine a coding template of themes. We used no a priori themes. Two team members (GC, SER for sons; GC, MDM for mothers) reread the transcripts and subsequently met to apply the codes systematically to all focus group data. Coded text was entered into NVivo software (version 8, QSR International Pty, Ltd., Doncaster, Victoria, Australia) to assist with analysis. During the analytic process, the research team reviewed, discussed, and incorporated the facilitators and observers' written notes.

\section{Results}

Three hundred fifty-four potential dyads were sent recruitment letters. Eight opt-out postcards were returned. Of the remaining 346 dyads, we

Figure 2. Recruitment of adolescent sons.

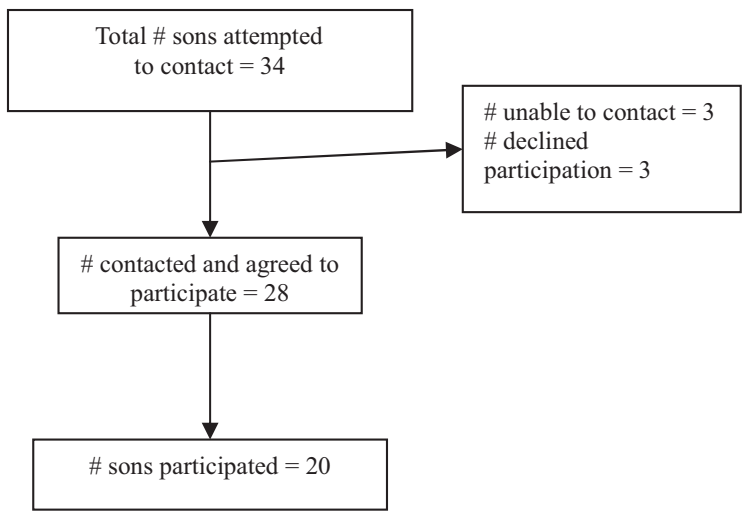


attempted contact with 301 . The other 45 dyads were not contacted because the groups were filled. Figures 1 and 2 illustrate recruitment.

In June 2008, 5 focus groups were conducted, 3 with mothers (2 in English, one in Spanish) and 2 with sons (both in English). A total of 22 mothers and 20 sons participated. Table 1 shows demographic characteristics of the group participants.

What we describe below are the key themes that emerged related to the PCP (including role, demeanor, and content or message from visit) and confidential care (including experiences with and attitudes about).

\section{Primary Health Concerns and Attitudes Toward the Role of PCPs}

\section{Adolescents' Perspectives}

Adolescents' major health concerns were overwhelmingly STIs and pregnancy prevention (Table 2). Overall, these adolescents had a limited perception of the PCP's role, which they believed included delivery of safe sex messages about STI and pregnancy prevention as well as condom distribution. However, the adolescents reported having already received harm reduction and safe sex messages from multiple sources, including family members and school. They reported that the PCP's safe sex discussion did not add much value to that message because, as a number of participants described and as the quote below illustrates, their doctors often delivered the message in a superficial and predictable manner. Instead of counseling, many thought the PCP's principal role was to perform STI testing.

"Nah, no discussion, there's nothing to discuss. [The doctor] going to tell me not to do it. Yes, I know all the bad things that could happen...I just want to know if I'm good or not then I'm out."

Adolescents valued encounters in which the PCP made efforts to connect with them and adopted a relaxed but concerned demeanor. This was described as "creating a vibe." The PCP's perceived empathy affected adolescents' comfort level and subsequent disclosure of high-risk behavior.

"If [doctors] act cool with you, you think they cool peoples, and then you should trust them. But if you don't think that they're cool, like probably that they going to tell your mom, then you don't tell them stuff... [doctors] should know bow to act cool like [asking] what's up, how you been, what you doing, bow's school...try to relate to us."
Table 1. Demographics as Reported by Adolescents and Their Mothers

\begin{tabular}{|c|c|c|}
\hline & $\begin{array}{c}\text { Sons } \\
(\mathrm{n}=17)^{*}\end{array}$ & $\begin{array}{l}\text { Mothers } \\
(\mathrm{n}=21)^{*}\end{array}$ \\
\hline Age, mean years (range) & $17.7(16-19)$ & $44(33-65)$ \\
\hline \multicolumn{3}{|l|}{ Birth country } \\
\hline Mainland United States & $16(94)$ & $12(57)$ \\
\hline Puerto Rico or Caribbean & $1(6)$ & $8(38)$ \\
\hline Other (Italy) & 0 & $1(5)$ \\
\hline $\begin{array}{l}\text { Age when arrived in the United } \\
\text { States (mean years [range]) }\end{array}$ & NA & $17(5-28)$ \\
\hline \multicolumn{3}{|l|}{ Employment $^{\dagger}$} \\
\hline Student & & $3(14)$ \\
\hline Employed part or full time & & $11(52)$ \\
\hline Homemaker & & $3(14)$ \\
\hline Medical leave & & $3(14)$ \\
\hline Retired & & $1(5)$ \\
\hline \multicolumn{3}{|l|}{ Estimated annual family income ${ }^{\dagger}$} \\
\hline$<\$ 20,000$ & & $7(33)$ \\
\hline$\$ 20,000-\$ 40,000$ & & $7(33)$ \\
\hline$\$ 41,000-\$ 60,000$ & & $2(10)$ \\
\hline $\begin{array}{l}\text { People currently in household } \\
(\text { (mean [range })^{\dagger}\end{array}$ & & $3.3(2-5)$ \\
\hline Son currently lives with mother & $17(100)$ & \\
\hline $\begin{array}{l}\text { Son has ever had a boyfriend or } \\
\text { girlfriend }^{\ddagger}\end{array}$ & $16(94)$ & \\
\hline $\begin{array}{l}\text { Son has ever had sexual } \\
\text { intercourse }\end{array}$ & $16(94)$ & $10(48)$ \\
\hline \multicolumn{3}{|l|}{$\begin{array}{l}\text { Timing of son's first intercourse } \\
\qquad(\mathrm{n}=16)^{\ddagger}\end{array}$} \\
\hline$<2$ years ago & $3(19)$ & \\
\hline 2 to 3 years ago & $2(12)$ & \\
\hline$>3$ years ago & $11(69)$ & \\
\hline \multicolumn{3}{|l|}{$\begin{array}{l}\text { Current frequency of son's } \\
\text { condom use }(\mathrm{n}=16)^{\ddagger}\end{array}$} \\
\hline Most of the time & $4(25)$ & \\
\hline Every time & $12(75)$ & \\
\hline $\begin{array}{l}\text { Son's lifetime partners (mean } \\
\text { [range]) }\end{array}$ & $5(1-12)$ & \\
\hline $\begin{array}{l}\text { Sons with a history of a pregnant } \\
\text { partner }\end{array}$ & $5(31)^{\S}$ & $2(10)$ \\
\hline Son is a father & 0 & $1(5)$ \\
\hline $\begin{array}{l}\text { Parent is aware their teen is } \\
\text { sexually active }\end{array}$ & $13(81)$ & $10(48)$ \\
\hline Son has ever been tested for STI & $12(71)$ & $10(48)$ \\
\hline Son ever diagnosed with $\mathrm{STI}^{\ddagger}$ & 0 & 0 \\
\hline
\end{tabular}

Values provided as $\mathrm{n}(\%)$ unless otherwise specified.

*Data missing for 3 sons and 1 mother.

${ }^{\dagger}$ Sons were not asked this question.

${ }^{\ddagger}$ Mothers were not asked this question.

${ }^{\S}$ One respondent did not know.

STI, sexually transmitted infection.

Some described the PCPs' demeanor and communication style as being either "professional" or disconnected, versus "real" or "personal." 
Table 2. Health Concerns Mentioned in Response to the Query, What are the Main Concerns That You/Teenaged Boys Have About Your/Their Health?

\begin{tabular}{lcc}
\hline Health Concern & Sons $(\mathrm{n}=20)$ & Mothers $(\mathrm{n}=22)$ \\
\hline $\begin{array}{l}\text { Pregnancy/pregnancy } \\
\text { prevention }\end{array}$ & $10(50)$ & $4(18)$ \\
$\begin{array}{l}\text { Sexually transmitted } \\
\text { infections }\end{array}$ & $8(40)$ & $15(68)$ \\
HIV/AIDS & $6(30)$ & 0 \\
Violence & 0 & $11(50)$ \\
"The streets" & 0 & $9(41)$ \\
Emotional/mental health & 0 & $9(41)$ \\
$\quad$ issues & 0 & $9(41)$ \\
Peer pressure & 0 & $6(27)$ \\
Chronic diseases & & $4(18)$ \\
Substance use/abuse & 0 & 0 \\
Genital health & $3(15)$ & $8(36)^{\ddagger}$ \\
Other & $5(25)^{\dagger}$ & \\
\hline
\end{tabular}

Values provided as $\mathrm{n}(\%)$.

*Asthma (3); autism (1); epilepsy (1); heart murmur (1).

${ }^{\dagger}$ Hygiene (2); obesity (2); chronic disease (1).

‡"Fast” girls (2); multiple sexual partners (1); domestic abuse (1); sexual abuse (1); homosexuality (1); meningitis (1); obesity (1).

"I'm comfortable talking to my doctor because I had bim for so long... when I talk to him about me and my sex life, be's professional but at the same time he steps out of that professional matter and keeps it real with me, keeps it a bundred...[Doctors] should at least relate to you. Whether it be a story or even if they have to make it up, relate to the patient."*

Additionally, a longitudinal continuity of care relationship added to the adolescents' comfort in disclosure.

"I was fortunate to have the same doctor for the last 9 years. So it was more comfortable for me to talk to bim...I can open up."

\section{Mothers' Perspectives}

Mothers' primary concern for their sons was STIs (mentioned by $68 \%$ ). However, they identified a range of issues that the PCP could address. Interestingly, pregnancy prevention was mentioned relatively infrequently, especially compared with their sons' reports (Table 2).

In keeping with their broader view of adolescent boys' health concerns, the mothers' perception of the PCP's role was broader as well. Many mothers were committed to ensuring an annual physical for their sons, during which they expected a clinical evaluation and discussion of preventive health is- sues. This included harm reduction education to reinforce and expand on the safe sex messages that their sons received at home.

The mothers generally indicated that they assumed their adolescent sons were or would soon be sexually active. Mothers viewed their role as protecting their sons from the harmful consequences of sex, especially STIs, but not prohibiting sexual activity altogether. As this mother describes, many indicated they actively promoted a harm reduction message.

"I give him condoms. I tell [my son]_I mean even if you're embarrassed, just tell me, 'Ma, I need [condoms]."I'm already in Wal-Mart buying [condoms]. Because I already tell [bim], 'Here, just take it. I don't want to know, just please protect yourself.' I can only just try my best to keep saying it over and over and over again."

Many recognized that adolescents may not fully communicate with parents or doctors about their sexual activity; thus, some suggested that the PCP's role included performing STI testing during all annual physical exams.

"Sometimes even the parents might not want [STI testing] and they say, no because my son does not have sexual relations and sometimes they do not even know it...That is why I think the doctor should have [STI testing] automatically as part of their physical."

\section{Experience and Attitudes toward Confidential Care Adolescents' Perspectives}

Almost all the adolescents had experience with confidential care. Although sexual activity was viewed as normative and most of the adolescents did not express overt concern about their mothers learning of their sexual experience, they felt that aspects of their sex life should be kept private, especially from their mothers. This attitude was noticeable even among those with apparent good relationships with their mothers, as described by this adolescent.

"My doctor he'd asked me, 'Would you want your mom to leave the room?' Me, off the bat I'm going to say yeah, because it's like me and my mom is cool, I talk to her, but it's not like every last aspect that she should be included in."

Reasons for adolescent's nondisclosure to their PCPs included desire to avoid the fatigue of hearing another safe sex/harm reduction message that added no new information to what they already knew.

\footnotetext{
* "Keep it a hundred" describes the quality of being genuine and honest, especially as it pertains to demeanor.
} 
"It's straight out of the book, guy doctors, girl doctors, they all say the same thing. 'Oh, if you want to get tested we can do this and this.' They never really tell you how they feel, what they feel. So, I feel it's no sense of talking to them."

Another issue affecting adolescents' decision to disclose was concern about the limits of confidentiality, especially with regard to personnel who worked in the health center who might find out about their health information or details about their sexuality and STI diagnosis.

"When it comes to any other subject other than sex, with a doctor I could feel comfortable. With a doctor even though they say it's confidential, they make you fill out surveys and stuff like that. It's guaranteed they're going to talk about it with another doctor or the nurse that helped you out. I feel like sometimes when they say it's confidential, it's not really confidential...it's in the folder with your name on it."

Moreover, some adolescents expressed a general level of distrust in the physician maintaining confidentiality. Some indicated that they lied to their PCP for this reason.

"In general, you wouldn't tell [your doctor] your business... I feel like he's going to tell my mom or whatever the case may be...I lied to my doctor plenty of times."

Despite this degree of mistrust and concern about information sharing, in general the participants seemed to trust their physicians' assurances of confidentiality and indicated that confidentiality assurances facilitated disclosure.

"If [doctors] didn't say it would be confidential, you might bold back and not tell them anything, so I think that's just the whole point of them saying it's going to be confidential...I feel like they won't say anything."

Many adolescents viewed disclosing as a sign of maturity, being responsible, and a means of facilitating better care; this was interpreted as a sign of "selfrespect." Disclosure increased with adolescents' increasing age. Teens viewed the advantages of confidential care as increasing the potential to discuss private information and to be honest with the PCP. Only one had experienced a direct breach of confidentiality by his physician; another described a breach when a bill outlining services received was sent to his home.

\section{Mothers' Perspectives}

In general, the mothers supported the provision of confidential care and time alone as useful for the adolescents to gain comfort with the physician, to discuss private issues, and for the PCP to counsel teens. Mothers recognized that their sons might disclose important health information only to the
PCP. However, many also described tension or conflicting feelings. Mothers talked about feeling left out, disrespected, or usurped in their role as protector and caretaker.

"If I don't know then how can I help him? How can I protect him or show bim bow to protect bimself if I'm not aware of the problem? The doctor's only there for what, that 10, 15 minutes of visit and that's it. Where's the doctor after he goes home?"

Of particular note, the mothers described feeling that confidential care sets-up a "double standard," contrasting their legal and moral responsibility as a parent and the need for parental consent for most medical services versus parental exclusion from certain conversations and situations.

"It is a double-standard....That you do have to sign their document so the clinics and hospital can get paid, but we're not entitled to know serious issues that may or may not happen with [our] children."

Mothers were especially uncomfortable with being uninformed about therapeutic decision making and with confidential care for younger teens. A lack of clarity about the limitations of confidential care, especially when and how they would be included in decision making, caused considerable distress.

Despite these conflicted feelings about confidential care, the conflict eased as teens got older. This was especially evident for those who indicated a continuity of care relationship with their PCP. As with the teens, mothers also valued the longitudinal continuity of care relationships. Some mothers described improved parent-teen communication after the visit as an outcome from a confidential care visit.

\section{Comment}

Despite connections to the health care system and recently accessing health care services, these adolescent males had a narrow perception of their health concerns and viewed the PCP's role as limited. To increase the relevance of primary care and to foster disclosure during health encounters, our participants described the critical nature of the doctor-patient relationship and physician demeanor, especially in the context of a continuity of care relationship. These qualities were recurring themes among adolescents who had disclosed risk activity to their PCP, as well as among mothers who felt most comfortable with confidential care.

Although the importance of provider demeanor has been documented in research with adolescents of both sexes, ${ }^{23}$ relationship building may be an 
especially important factor here because adolescent males describe health as relatively low on their list of concerns. ${ }^{24,25}$ Even when adolescents identify a health care issue for which they would like more information, few adolescents (especially boys) identify a physician as a primary source. ${ }^{26}$

We included mothers in our study because parents play a key role in the health care-seeking behavior of their children, including adolescents, and the process of confidential care must take into account parental concerns. In a study exploring maternal expectations of the PCP in adolescent health care, it was shown that mothers want the PCP to communicate with the adolescent, encourage healthy behavior, and maintain teens' confidentiality while keeping communication open between the PCP and mother. ${ }^{27}$ Our mothers seemed to appreciate the importance both of family communication and of the PCP's role in their son's health. They were markedly focused on STI, not pregnancy prevention, and described a proactive approach to protecting their sons from STIs. However, our mothers had mixed feelings about the provision of confidential care. In contrast to concerns about the PCP discussing inappropriate information during confidential conversation with their daughters, ${ }^{19}$ mothers' conflict around confidential care with their sons related to feeling excluded from important therapeutic decision making and dismay about a perceived double standard between the parental role and the responsibility of medical care. When PCPs introduce the concept of confidential care, it could be helpful to include more clear discussion and education about the purpose of confidentiality with both adolescents and their parents. ${ }^{28}$

Time alone during a visit was a near universal experience among our sample. However, when asked about disclosure, the adolescents described many reasons for not disclosing risk behavior to their PCP, including to avoid being lectured. These adolescent boys' relative lack of concern about confidentiality breaches to family members was unanticipated. This is likely related to traditional gender roles, which endorse a view that adolescent boys should be sexually active, compared with young women who are expected to remain sexually abstinent until adulthood. ${ }^{19}$ Instead, our respondents expressed concerns about the PCP discussing sensitive information with health center staff, a concern that was also found in other studies. ${ }^{23}$ PCPs may want to discuss with adolescents the concept of "medical teams" (including nursing and other ancillary support) in the provision of all medical care. One adolescent experienced a breach of confidentiality because of billing systems; this suggests the need to educate clinicians and their staff about the explanation of benefits from insurance companies and to develop systems to minimize these risks.

Study limitations include sampling bias. The results reflect a group more connected to primary care than is the case for an average adolescent. Compared with adolescents who are not connected to health care, we might expect that our focus group participants would ascribe a more important role to the PCP and fall into a lower-risk group. Additionally, the recruited sample was reachable by phone, which likely resulted in a group of higher socioeconomic stability compared with health center users whom we could not reach. A second limitation is that we only included individuals in the Bronx, NY. Adolescents and their mothers in different geographic locations are likely to have variable exposure to harm reduction and safe sex messages outside their PCP's office. Other limitations include the relatively small number of groups conducted and the exclusion of younger adolescents. It is unclear if we reached saturation. ${ }^{20}$ More themes might have emerged with a greater number of groups or with the inclusion of younger adolescents, though this was not financially feasible. However, the purpose of qualitative research is to generate hypotheses, as was done here, rather than to generalize statistically to the larger population.

\section{Conclusions}

These findings have several implications for the provision of time alone with a PCP and familial comfort with confidential care. Discussion of the purpose and limitations of confidentiality both with parents and with adolescents could lead to greater parental comfort with confidential care and increased adolescent disclosure. Regular, routine confidential care should start early in adolescence. Additionally, PCPs must find ways to increase their perceived relevance to adolescents. One way is by exploring the manner in which the harm reduction message is delivered; it is essential to look for ways to develop messages that will be perceived by adolescents as personalized, not redundant, and that offer adolescents the chance to ask questions that reflect their sexual health concerns. Another way is by fostering a continuity of care relationship. A focus on rapport building is of paramount importance. We must continue to enhance clinician skills in rapport building with adolescents during residency training and through continuing medical educa- 
tion. Ideally, this would take an interactive, multimedia approach $^{29,30}$ emphasizing lessons learned from youth. Given the many reasons cited for nondisclosure, future research should measure disclosure as a marker of the quality of the doctor-adolescent interaction.

\section{References}

1. Eaton DK, Kann L, Kinchen S, et al. Youth risk behavior surveillance-United States, 2007. MMWR Surveill Summ 2008;57:1-131.

2. Lawrence R, Gootman J, Sim L, eds. Adolescent health services: missing opportunities. Committee on Adolescent Health Care Services and Models of Care for Treatment, Prevention, and Healthy Development. Washington D.C.: The National Academies Press; 2008.

3. Gavin L, MacKay A, Brown K, et al. Sexual and reproductive health of persons aged 10-24 years-United States, 2002-2007. MMWR Surveill Summ 2009;58:1-58.

4. Lehrer JA, Pantell R, Tebb K, et al. Forgone health care among US adolescents: associations between risk characteristics and confidentiality concern. J Adolesc Health 2007;40:218-26.

5. Klein JD, Wilson KM, McNulty M, et al. Access to medical care for adolescents: results from the 1997 Commonwealth Fund Survey of the Health of Adolescent Girls. J Adolesc Health 1999;25:120-30.

6. Cheng TL, Savageau JA, Sattler AL, et al. Confidentiality in health care. A survey of knowledge, perceptions, and attitudes among high school students. JAMA 1993;269:1404-7.

7. English A, Ford CA. More evidence supports the need to protect confidentiality in adolescent health care. J Adolesc Health 2007;40:199-200.

8. Ford CA. Which adolescents have opportunities to talk to doctors alone? J Adolesc Health 2010;46:307-8.

9. American Medical Association Department of Adolescent Health. Guidelines for adolescent preventive services (GAPS). 2008. Available at: http://www.ama-assn.org/ ama/upload/mm/39/gapsmono.pdf. Accessed 16 March 2010.

10. U.S. Preventive Services Task Force. Behavioral counseling to prevent sexually transmitted infections: US Preventive Services Task Force recommendation statement. Ann Intern Med 2008;149:491-6.

11. Ford C, English A, Sigman G. Confidential health care for adolescents: position paper for the society for adolescent medicine. J Adolesc Health 2004;35:160-7.

12. Meyers D, Wolff T, Gregory K, et al. USPSTF recommendations for STI screening. 2008. Available at: http://www.uspreventiveservicestaskforce.org/uspstf08/ methods/stinfections.htm. Accessed 28 September 2010.

13. Committee on Adolescence. Achieving quality health services for adolescents. Pediatrics 2008;121:1263-70.

14. Selden TM. Compliance with well-child visit recommendations: evidence from the Medical Expenditure Panel Survey, 2000-2002. Pediatrics 2006;118:e1766-78.
15. Marcell AV, Klein JD, Fischer I, et al. Male adolescent use of health care services: where are the boys? J Adolesc Health 2002;30:35-43.

16. Marcell AV, Ford CA, Pleck JH, et al. Masculine beliefs, parental communication, and male adolescents' health care use. Pediatrics 2007;119:e966-75.

17. Burstein GR, Lowry R, Klein JD, et al. Missed opportunities for sexually transmitted diseases, human immunodeficiency virus, and pregnancy prevention services during adolescent health supervision visits. Pediatrics 2003;111(5 Pt 1):996-1001.

18. Martinez GM, Chandra A, Abma JC, et al. Fertility, contraception, and fatherhood: data on men and women from cycle 6 (2002) of the $2002 \mathrm{Na}$ tional Survey of Family Growth. Vital Health Stat 23 2006;(26):1-142.

19. McKee MD, O'Sullivan LF, Weber CM. Perspectives on confidential care for adolescent girls. Ann Fam Med 2006;4:519-26.

20. Crabtree BF, Miller WL, eds. Doing qualitative research (research methods for primary care, 2 nd edition. Thousand Oaks, CA: Sage Publications, Inc.; 1999.

21. Edman JC, Adams SH, Park MJ, et al. Who gets confidential care? Disparities in a national sample of adolescents. J Adolesc Health 2010;46:393-5.

22. Berg B. Qualitative research methods. Needham, MA: Allyn \& Bacon; 1998.

23. Ginsburg KR, Menapace AS, Slap GB. Factors affecting the decision to seek health care: the voice of adolescents. Pediatrics 1997;100:922-30.

24. Marcell AV, Raine T, Eyre SL. Where does reproductive health fit into the lives of adolescent males? Perspect Sex Reprod Health 2003;35:180-6.

25. Marcell AV, Halpern-Felsher BL. Adolescents' health beliefs are critical in their intentions to seek physician care. Prev Med 2004;41:118-25.

26. Ackard DM, Neumark-Sztainer D. Health care information sources for adolescents: age and gender differences on use, concerns, and needs. J Adolesc Health 2001;29:170-6.

27. Ford CA, Davenport AF, Meier A, et al. Parents and health care professionals working together to improve adolescent health: the perspectives of parents. J Adolesc Health 2009;44:191-4.

28. Hutchinson JW, Stafford EM. Changing parental opinions about teen privacy through education. $\mathrm{Pe}-$ diatrics 2005;116:966-71.

29. Marinopoulos SS, Dorman T, Ratanawongsa N, et al. Effectiveness of continuing medical education. Rockville (MD): Agency for Healthcare Research and Quality; 2007 Jan. Evidence Report/Technology Assessment No.: 149. Contract No.: 290-02-0018. AHRQ Publication No.: 07-E006.

30. Albanese M, Mejicano G, Xakellis G, et al. Physician practice change II: implications of the integrated systems model (ISM) for the future of continuing medical education. Acad Med 2009;84:1056-65. 